\title{
Rise and Fall of Metaphors in Literary Translation: A Theoretical Review
}

\author{
Moh. Supardi \\ Program Studi Bahasa dan Sastra Inggris \\ Universitas Islam Negeri Syarif Hidayatullah Jakarta \\ Tangerang Selatan, Indonesia \\ moh.supardi@uinjkt.ac.id
}

\begin{abstract}
Translating metaphors from one language to another language is one of the most difficult task for translators since the main problem is not only recognizing, but also understanding and differentiating metaphoric from nonmetaphorical usage. Regarding to the issue, this article sheds light theoretical views over metaphors in literary text translation. As a matter of fact, it is seeking to discuss metaphors that, probably, 'loss' or 'gain' ('rise' or 'fall') in translation, e.g. English to Indonesian. In order to fitting out to the topic of discussion, the writer provides extended examples. Nonetheless, this article does not in- depth analyzes students' translation, but rather to review theoretical metaphors of literary text translation spoken in general terms. After all, this article has a good mind to simply roll out light comments on students' literary translation theories in term of metaphors that seem to be unnatural, i.e. mostly lost (or found?) intranslation.
\end{abstract}

Keywords - Concept, theory, metaphoric word, literary text, poem, lost in translation.

\section{INTRODUCTION}

Translating metaphors can be very complicated since human as individual or social being has a different background of knowledge, culture, norm, value and taste that may vary one with another, since the human way of thinking, by its nature, is metaphorical [1]. Metaphors as a way of understanding the concept from one language to another language may shape different metaphorical expression that can lead to difference or loss of metaphor[2, p. 1256]. This article aims to review metaphorical translation theory of English-Indonesian poems done by students of English Language and Literature Department of Adab and Humanities Faculty at Universitas Islam Negeri Syarif Hidayatullah Jakarta. How do they distinguish characteristics of metaphors in a poem? How do they create aesthetical value and image from source language to target language poem? How are metaphors translated from English to Indonesian? What metaphors from source language that are translated (raise) and not translated (fall) in the target language? these questions are important and significant to be discussed in terms of the theoretical level to build an understanding of metaphoricaltranslation.

This article is the further discussion of previous short story translation, South of The Slot, conducted in 2016. In fact, most students translated the story literally or faithfully rather than communicatively, particularly in translating metaphorical expressions from source text into target text, for example, "He... and treated her to oysters" (The Library of America, 1982: 827), which was translated into Bahasa Indonesia $I a$... dan menraktirnya makan kerang. The 'oysters' is a conceptual metaphor for 'a wife' that can be expressed in variety of ways according to some histories or due to some causes, such as cultural references, communicative purpose, functional concern, information content, metaphor variety, cotext and context constrain, level of competence of the conceptual and formal structures of the two languages engaged, living synchronic norms, level of metaphor lexicalization, translator's capability, connotations, level of an isomorphism between the source and target domains in both cultures, metaphor understanding, the role of cognitive, etc., might have an impact on translation of metaphors. The purpose is to obtain some aesthetical and rhetorical effect, to communicate elegantly, to attract others with 'beautiful' articulately pleasing statement, or to show some rich image[3]. So, based on the context of the text, the translation for "He... and treated her to oysters" should be translated into Ia ... dan langsung memeluk/mencumbunya for "he" has been a long time didn't see his girl friend and the word 'oysters' is, basically, metaphorical usage to create aesthetical value to attract others' attention.

Many articles and studies discuss metaphors. The perspectives of metaphorical translation also discussed by several writers, such as Pamela K. Morris from Loyola University Chicago, Jennifer A. Waldman, and Bowers and Osborn (1966) who describe the correlation between metaphors in speeches and shift in attitudes. Particularly, gender metaphors, martyr, and a mixture were tested, and the findings can be classified into three categories: First, not all metaphors pose certainty. Second, the metaphor association to the audience makes a distinction, and third, the connection of the metaphor to the speech structure also requires to bereviewed.

Metaphors might pose a problem in translation, for transmitting them from one language and culture to another may be caused mainly by the linguistic and cultural 
distinction[2]. Based on metaphorical studies and literature reviews, it can be inferred that metaphors principally play a significant role in developing human thought. Feldman, Inns and Jones stated that metaphors can help synthesizing and integrating the ramification and confusion of human organizational experience[4]. Metaphors allow the formulation of concept to "recognize the new world." This internally genuine metaphors perspective used as the reason for the intensive use of metaphors in system studies and their importance to research and theoretical framework. Metaphors can identify between invisible things and visible things and between the abstract to the concrete. This process cannot be put aside from the constructive conception that poetically cobuilds the 'object' [1], [5]-[9].

In spite of the problems, the metaphor is an inevitable reality of translation that must be faced by translators. Some critics, however, claimed that translating a poem from one language to another language can be merely conducted by those who are experts in the field (poets). Otherwise, the beauty of source language poem will be lost in translation [4]. Regarding this notion, this article seeks to shed light on the theoretical frameworks of translating a poetry, especially the metaphorical translation. The metaphor is very influential, but it is a likely difficult instrument for students to construct that probably may lead to the 'loss' (found?) of metaphor translation.

\section{LOST AND FOUND}

The concept of rise and fall as mentioned in the title of this article was adapted from lost and found concept used in several fields, such as Alzheimer diseases, security and office policy, retirement savings, and so on.

\section{A. Lost and Found in Alzheimer}

According to the National Institute on Aging (NIA), for about 5.1 million Americans recently get Alzheimer's disease, on the contrary, the incensement of brain dispute that destruct the function of mind and brain. It is the reasons that thosewho suffer from dementia begin to lost. Study concludes that many people get lost to find their home[5]. Therefore, government tries to place missing adults who suffer from dementia experiencebetter solution that have been applied to find lost children[6].

A non-profit body with a national range that is addressing this issue is "A Child is Missing" (ACIM). The organization was established in 1997 for there is no such social-based program occurred at the time to give this goal. ACIM's Alert Program applies the following things: Someone phones the police station to report a lost child, elder people or adults who are disable, or someone with Alzheimer's disease; ACIM creates a recorded message with the information that has been supplied, comprising someone who see the; ACIM will put the entry location into the computer and gathers a database of phone numbers of nearby residents/businesses; ACIM will send out the recorded message by telephone to the community. ACIM also asks by telephone to reach the officer on the scene for additional information and to follow up until the lost person that has been found.

This concept then adapted in translation, since they share the same things in common. A translator like the Alzheimer dementia also can get lost in transferring a meaning from one text to another text or from one language another language. http://www.achildismissing.org/about.asp.

\section{B. Retirement Savings Lost and Found}

In 2016, there was an Act Sponsored by Senators Elizabeth Warren and Steve Daines since employers have changed from defined benefit pensions to individualized retirement plans, labors are responsible for tracing, cultivating, and consolidating multiple retirement accounts as they move from one place to another place. Transferring an account from an employer to employer is not easy, there are many workers who never get around to it. And as a consequence, the management company of investment counted that by 2015 , $30 \%$ of employees - tens of millions of Americans - had left their account of retirement at their previous employer (http://www.gao.gov/assets/670/667151).

This issue is just expected to flow in the coming years for two considerations:

a. Many young workers this time change their jobs much higher rates than their previous counterparts. The median job tenure for workers between 25 and 34 is just 3 years, so workers might multiple variety of different employersponsored retirement accounts throughout their working.

b. The development in employers' use of auto registration since the passage of the 2006 Pension Protection Act has resulted in a significant improvement in several small accounts - sometimes without employees even realizing they have one. It is not surprising, some of these small accounts are lost or ignored.

The Act in 2016 of Bipartisan Retirement Savings Lost and Found creates a national lost and found for retirement accounts. The data of employers are needed to report to the Treasury Department to create a national, online, lost and found for Americans' retirement accounts.

\section{Lost and Found Policy}

The other concepts that are adapted as translation is lost and found policy applied in guest room and are to be used to store valuable items. But, the hotel is not responsible for the theft, loss, damage or destruction of the property in the absence of gross ignorance on the part of the Hotel or its guests. A Hotel obeysguidelines and directions mandated by the Police such as:

a. Lost items are reported to the lost and found department with the description, date and time found, someone who found it, and the details. It is better to give advise that the lost and found item will be kept for 30 days at the property and then given out toPolice. 
b. Shoes, clothes and the resemble items: Reported to the lost and found office with the description, time and date found, someone who found it, and the details. If it is no guest detail. Please be advised that the lost and found item will be kept for 30 days at the property and then given out to charity as guided byPolice.

c. The fragile items and liquor: Reported to the lost and found office with the description, date and time found, someone who found it, guest full details (if found in the guest room) otherwise no guest details if found in public areas. It is suggested that the lost and found item will be directly disposed in the presence of the Security Manager or Manager on Duty as mandated by thePolice.

The property left in or next to the dust bins are considered rejected and will be ignored. Therefore, a Hotel is not responsible for items that lost. It is encouraged to avoid destruction by locating the items in the drawers and cabinets provided, or in their luggage (warwickhoteldubai@warwickhotels.com).

\section{METAPHORLOST}

Metaphor is a structure of thought which is usually used by a certain speakers or community.The figurative meanings is applied to give creative description or a special effect. In this case, the meaning of individual words in an expression has no correlation with the understanding of the meaning. For such meaning indicates idea of figurative meanings such as metaphors. In every day language, metaphors have a wide extent use, and they are considered as one of the most frequently used as means of figurative expression. At this level, the English as foreign Language learners do their best to use and, especially, to translate metaphors correctly and efficiently in order to obtain metaphoric and to give impression like a sourcetext.

In spite of the problem that current increase intheory of translation and application, metaphors still pose a serious handicaps for foreign learners. The other problem is not only found in transferring the meaning of metaphoric word, but it also happens when they have to identify and differentiate between the metaphoric expression with the nonmetaphorical one. Basically, there are so many metaphors which have different orientation between countries to another countries that lead into different way of using symbol of metaphors. Therefore, translating metaphors from one language to other languagescan lead to the 'loss' and 'gain' or 'rise' and 'fall,' especially when the text contains recent metaphors or neologisms that are only known by a small community or author's own terminology.

Pamela quoted Siltanen[7], [8] who suggested that in order to have their passion effect, concepts within metaphors must give significant meaning to participants. Even though the research discusses metaphors in speeches, findings can be applied to literary translation including novel, poem, and other prose, as expressive text. Metaphors, which are embedded in language and the human cognitive system, can offer a systematic review of language and give insights into culture. Therefore, the investigation of metaphors is not enough without understanding the relationship of culture and language. Metaphors areblended in language and that is why it is understood by our world-from portraying attitudes to defining objects. Sapir as cited in Nelson and Hitchon[9] showed that metaphors, together with irony, synecdoche, and metonymy, are considered a master trope, "a figurative language that defines a relationship amongterms."

According to Lakoff and Johnson[1] metaphors is understanding one concept in terms of another, that abstractions, such as emotion and feelings, are usually described through physical experiences. According to Foss and Trapp as it is quoted by Kaplan[10]stated that metaphors consist of two main parts: "tenor," or the main subject, and "vehicle," which transfer qualities of one idea to another. For instance in the metaphor "dreams are chocolate," dreams are the tenor and chocolate the vehicle. Metaphors develop concepts beyond experience and need to draw our imaginations to build meanings. The notion has attracted scholars in linguistics, philosophy, anthropology, and psychology[9]. Aristotle as cited in Leary[11, p. 268]described metaphor as "giving names to previously nameless things . . . our best means of getting hold of something fresh," and he wrote that "the greatest thing by far is to be a master of metaphor."

Comply with Hanafi's opinion "the problems of poetry translation lies upon linguistic aspects, barriers of cultures, literary devices and poetic characteristics" (2003, p.28). For the understanding of poetry is a multi tasking, the process of poetry translation is considered as a complicated process. Along with the personal process, the translator probably will find several words which are untranslatable due to availablelinguistic and cultural distinctions among language systems. Therefore, it is suggested that a poetry translator needs to translate in an easy ways as the reasons. According to Jackson, literary translation is different from the translation types practiced in a class of language. according to him, literary translation brings a good deal of interpretation as well as difficulty to translate the response, tone, mood, voice, sound, etc.

Literary texts, according to Newmark,are mostly concerning to persons, i.e. implicitly dialogues between firstand second person. While non-literary texts are about objects, normally for the third person. Literary text are closely related to allegorical aspects, therefore moral truth and literary words are written to be read soundlessly or skimmed. The gist of literary texts is the original or imaginative metaphor, but the core of non-literary texts is the standard or explanatory metaphor and the common words. Literary texts are written to be read aloud in the mind, to be judiciously read repeatedly, and increasingly appreciated; the sound of non-literary texts is often ignored, and they are read quickly (2004).

According to Perrine, even the primitive people have used poetry and it has been written and listened to by different people. The poet, forms his/her own store of felt, observed or imagined experiences, selects, combines and reorganizes. So, the poet deals with his/her deep experiences and expresses 
them in his/her poetry. What makes poetry distinctive from prose is the fact that Poetry contains both literary and musical features. It consists of a combination of metaphor, simile, imagery, symbol, allegory and even narrative story line, etc. Also denotation or direct meaning and connotation or indirect meaning, both assist to form the sense of poem. According to Deedari, the reader of a poem should go beyond the plain literal meaning or denotation of a poem's words if $\mathrm{s} / \mathrm{he}$ wants to catch the whole meaning. Hence, if the readers do not pay enough attention to the words' connotation they miss a great deal. Literary texts have unique style of writing and distinctive language. Literary texts are like the umbrella term for various genres like drama, short story, novel and poetry. Since poetry is one of the subdivisions of literary texts and the current study is in relation to poetry translation, it needs to be definedseparately.

\section{IV.METHOD}

The discussion of theoretical review on metaphorical translation done by 26 students of English Language and Literature Department of Adab and Humanities Faculty at Universitas Islam Negeri Syarif Hidayatullah Jakarta will be analyzed qualitatively and the theoretical concept will be described descriptively. While the theories of metaphorical expression will be discussed based on the "loss" and "gain" of metaphors concepts and theories from many perspectives. Since the goal of this paper just to review theoretical framework of metaphor, the method used in this paper is only highlight the metaphorical concept taken from several sources. Concepts of metaphor that lost and found are analogized as rise and fall which analogized from the concepts of security lost and found, Alzheimer concept, and so on. While the theoretical concept of translating poetry were taken from translation poetry concept from several sources.

\section{Result AND DisCUSSION}

\section{A. Is a Poetry Translatable?}

According to Bartens[12, p. 21], the current opinion of the poem is considered as a means of insignificant. Compatibility is made for contradictions and a poem tension. Those are due to the internal organization or formal structureof a poem. On the other hand, Poem as it is defined by Cudden in the following ways: A poem is an art work, a text, a work of verse, that may be expressed in rhyme or may be in blank verse or a mixture. Probably, it is depended on a fixed number of syllables (p.678). it is stated in Random House Unabridged Dictionary[13] as "the art of rhythmical composition, written or spoken, for exciting pleasure by beautiful imaginative or elevated thoughts".Poetry is the expression of feelings experienced by a poet[4, p. 9]. Nair states that "poetry is an imaginative rendering of a poet's feelings and experiences." Therefore, "Poetry cannot be translated."

On the other hand, there are many people who can not accept the poetry translation. For example, Bashevis, as cited in Miremadi, discuss about the necessity of literary (poetry) translation as he states "translation undresses a literary work, its real honesty. A writer can blame himself in his own language, but some of his shortcomings become clear to him in another language. Sometimes, a poemtranslator conveys the bitter truth. It discovers all masks"[12, p. 35]. In general, it is not suggested to hold from translation of poem, for a poetry is the tools of expression of someone's attitude and feelings toward world affairs. The translation, in this case, may function as a mean of bridging to bring the differences of theworld.

According to Dryden in Miremadi, stated that poetry can be translated. He considered that to alter a poem, the translator should be a totally poet[12, p. 85]. He seems to pay much attention to the style, or formal features of the original poetry. Besides, Rose states "The translator of poetry must be fluent in and sensitive to the source language; he should know the source language's cultural pattern, its syntax, etymologies, and grammar, as well as its poetic tradition. In addition to that, he should culturally and politically identify himself with all his heart the original poet. He should penetrate the exteriority of the original text and lose himself in its intertextuality. In order to make the translation become a poem, the translator should also fulfill the hope and sensitivity of the poetic tradition of the readers. Therefore, the successful poetry translators are usually those who have bilingual and bicultural poets for the readers" (p.136).

As a matter of fact, it is true that translating poetry is a matter of sensibility, the aesthetic aspects of the original poem cannot be transferred into the readers. It indicates that although translating poetry is more attractive than other types of texts, it doesn't mean that translation of poetry is impossible. That is why, translators of literary texts, especially poetry, should have at least some degree of artistic genius. There are some different ways which translators can apply in translating poetry. In spite the words seem simple and clear on the surface, nonetheless, they have some connotative meanings. Although a word has been translated literally and the denotative meaning of them applied without any attentiontothe connotation, the readers may can not get what is the meaning supposed by the poet. It is suggested that the translator can add some extra explanations to every stanza in the form of footnotes or at the end of poem in order to avoid the loss of meaning because of differences in culture. The important device in every stanza is imagery. Words may seem simple on the surface but their collocation with each other sometimes makes no sense. In Persian, for example, readers even require some explanations to understand what is in the mind of the poet. That is why, as we call it defamiliarization, that is, words are used connotatively.

In general overview of the students' poem translation, the words translated from English into Indonesian seem to have source language orientation which are not merely belonged to the poetic language for readers' culture. Therefore, words are mostly simple and familiar (like stone, bubble, rock, etc.) and mostly abstract. Literary translation is often the connotation of words which is very important, language is idiolect, synonyms 
are differentiated, every sound is alive and its meaning might be in contradict to the sense. Every culture is unique and different, cultural translation is a difficult but the task is possible. Venuti (1995) states that translation strategy based on an aesthetic of discontinuity can best kept those differences, that others, by reminding the reader of the gains (found/rise) and losses (fall) in the translation process and the gaps between cultures is unbridgeable."

The lost and found concept are actually metaphor by the terms that are developed by 'gains' and 'loss.' The terms are then adapted in this article 'rise' and 'fall' as metaphor for the missing meaning that the original text writer wants to convey. On the contrary, the meaning is raised when the translator add some more explanation that is not exist in the original text. Such the overwhelming terms can be found in translation theory proposed by some linguists or translation experts. For example Catford (1960) prefers to use 'shifts' rather than 'transposition' as Newmark terms (1980).

\section{B. A Poetry Lost in Translation}

The requirement for the best representatives of Indonesian culture in the field of art and literature is the definite evidence from the dialogue need in the sphere of spiritual. Such this process, an important role is played by the translator who builds a bridge between two foreign poetic cultures. Therefore, translation is the very significant in the process of interrelations of literatures. A good translation of any text from one language into another means not only a simple translation of separate words and sentences, it also considers adaptation and interpretation to consider the distinction not only between languages, but it is also among readers' cultures. May be no other form can delivers an understanding of foreign- language text, as verse translation. It is specific; for the poetic language structure is very complicated. Even it is more crucial than natural language[14, p. 17].

The sensational and associated world indicates an important part of any culture. In the making process of the original text, the translator goes through a number of perception stages, from obtaining outline background of the original text to the high level when this perception becomes systematic. This approach can make it possible to enter the typological signs area of psychology in translational activity and at the same time a literary translation is considered as a formation causes of internationalpoetics.

Considering the two stages originating from differences in the socio-cultural circumstances and non coincidence ofstagesin development of English-Indonesian literatures, the attention of the students is drawn to the fact that perception of foreign literature, especially poetry, to take the readers in the rise of different world views, creative thinking tradition, images, ideas, the original author's emotion, when the text is seen as immanent closed structure. In time, it can lead to scoping and unequal perception degree of aesthetic information.

From the poetry assignment given to the students, the poetry seems to give different symbols and metaphors makes the poem not only difficult to understand and to translate it into another language. A sole comprehension of a text is not enough, a translator should put in an additional aesthetic effort to get deep feeling of the poem as the poet's representation, philosophy, and view.

In the first line of the original text the antithesis used by Louisa May Alcott in her poem "The Jumbles" (image of the jumbles is contrasted with the sieve which occupy different entity) can not meet the expression in the translation into Indonesian in students translation. The jumbles, which symbolizes freedom, for the extinction of a sieve is equivalent to extinction of freedom, and the latter equals decline of freedom itself. Snowstorm as an element does not spread beyond the corners, in the original poem the persistent repetition of jumbles ....

Edward Lear uses metaphor in the next stanza (in the shade of the mountains brown / far and few, far and few ; di bawah naungan pegunungan coklat / dari jauh, di kejauhan) in the translation the noun mountain brown is just coincided with the phrase expressed inpegunungan coklat/ which seems to be lost in Indonesian readers' culture. Such metaphor might be translated into metaphorical usage into tembok-tembok raksasa menghadang, for Indonesian use that metaphor to show the problems that can block theirlife.

As a result of replacing mountains brown, the image of the mountains disaster is reduced in target readers. In addition, the word repeated several times and "they went to sea in sieve" is the very important that can structure the whole poem, whereas in the translation it's given only twice, which can destruct not only the unity of the verse composition, but also obscures the clear description of the purpose. The word is again modified in the last stanza. The eternity image and faith are declined to the ordinary language - dan kami pergi ke laut dalam saringan. The symbolic and metaphoric nature begin to lose and also the space of the 'sieve' is reduced, and not without the help of translators the image dissolves. The Indonesian version doesn't feature the light journey as well as the adventure indication of the originalpoem.

To sum up the discussion above, the word is a shared, general communication tools and to bring them to understand that a translator should try to create a sense of wonder atthe words beauty, at their ability and diversity to create unique aesthetical images, especially when someone wants to a master in English poetry translation. As we already know that poetry presents the poetic word, nonetheless it is very difficult task to reveal the artistic value beneath the words of poetry. Translating English poetry can ensure people that it has extraordinary power, by bringing the sensations and association of world. Even though in the reality there is no one, nor even the experts, canaccommodate the meaning and intention of the author.

\section{CONCLUSION}

Based on the above overview, it can be inferred that metaphorical translation is considered important, particularly the relation between a metaphor and a specific culture becomes the main handicap to obtain metaphor equivalence. Regarding 
this problem, students/translators should try to reconstruct the complicated conceptual metaphors in a text. Therefore, a poem translator should consider metaphor and readers' culture. As a result, it is better to reconstruct the equivalence of experience in the context of metaphor translation to reformulate the metaphor together with cultural translation in the target text. A poetry translator can not ignore cultural aspects of readers. Therefore, It is advisable to conduct further research on the students' translation, especially concerning with metaphorical translation which in this article only to overview theories of translating metaphors which could be 'lost' and 'found' (raise and fall).

\section{REFERENCES}

[1] G. Lakoff and M. Johnson, Philosophy in the Flesh: the Embodied Mind and its Challenge to Western Thought. New York: Basic Books, 1991.

[2] C, Scaffner, "Metaphor and Translation: Some Implications of a Cognitive Approach," J. Pragmat., 2004.

[3] Z. Kövecses, Metaphor: A practical Introduction. Oxford: UK: Oxford University Press, 2010.

[4] M Feldman, in The Meaning of Ambiguity: Learning from Stories and Metaphors. In Re-Framing Organizational Culture, ed. P.J. Frost, L. Moore, M. Louis, C.C. Lundberg, \& J. Mar-tin, Thousand Oaks/CA: Sage, 1991.

[5] B Butler and Barnett B, Window of Wandering. Geriatric Nursing. 1991.

[6] Kirk Johnson, More with Dementia Wander from Home. New York: New York Times, 2005.

[7] Pamela K Morris and Waldman A Jennifer, "Culture and Metaphors in Advertising," Int. J. Commun., 2011.

[8] S. A Siltanen, "The Persuasiveness of Metaphor: A replication and Extension," South. Speech Commun. J., 1981.

[9] M. R Nelson and J. C. Hitchon, "Loud tastes, Colored Fragrances, and Scented Sounds: How and When to Mix the Senses in Persuasive Communications," Journal. Mass Commun. Q., vol. 76, no. 2, 1999.

[10] S. J Kaplan, "Visual Metaphors in the Representation of Communication Technology," Crit. Stud. Mass Commun., vol. 7, no. 1, 1990.

[11]D. Naming Leary, "Giving Forms to Things Unknown. Social Research, Retrieved from Academic Search Premier Database," vol. 62, no. 4, 1995.

[12]M. R Nelson and J. C Hitchon, "Theory of Synesthesia Applied to Persuasion in Print Advertising Headlines," Journal. Mass Commun. Q., vol. 72, no. 2, 1995

[13]J.A Cudden, The Penguin Dictionary of Literary Terms and Literary Theory. England: Penguin Reference, 1976.

[14] Y Lotman, Analysis of Poetic Text. Verse Structure. Leningrad: Uchpedgiz, 1972. 